\title{
EVALUATION OF BLUNT ABDOMINAL TRAUMA SEVERITY SCORE (BATSS) IN PREDICTING THE NECESSITY OF LAPAROTOMY FOR ADMITTED CASES WITH BLUNT ABDOMINAL TRAUMA
}

\author{
By
}

\section{Ismael Ragab El-Said Beltagy, Mahmoud Mohammed Abo Al-Yazid and Eslam Taha Ghalwash}

\author{
Department of General Surgery, Faculty of Medicine, Al-Azhar University
}

Corresponding author: Ismael Ragab El-Said Beltagy,

E-mail: ismaelbeltagy1235@gmail.com

\begin{abstract}
Background: Abdominal trauma is the third leading cause of death in trauma patients and can be found in about $7-10 \%$ of the total number of trauma cases. The Blunt Abdominal Trauma Scoring System (BATSS) provides a high-accuracy score system for diagnosing injury to intra-abdominal organs in blunt abdominal trauma patients based on clinical features, such as patient history, physical examination.

Objectives: To determine Blunt Abdominal Trauma patients 'signs, as well as clinical data, and to clarify the accuracy, sensitivity, specificity, positive and negative predictive value of Blunt Abdominal Trauma Severity Score (BATSS).

Patients and methods: This was a cross sectional study that was conducted on 100 cases admitted with bunt abdominal trauma in Al-Hussein Hospital, Al- Azhar University from March 2020 to October 2020, which included 50 males $(50 \%)$ and 50 females $(50 \%)$, their ages ranged from 18.0 to 60.0 years (mean \pm SD 38.53 \pm 12.11 ); included majority of cases from 20 to 40 year $(54 \%)$, after initial resuscitation and achieving hemodynamic stability, All patients were subjected to careful examination, and all patients underwent the FAST ultra sound and plain radiograph of chest and abdomen scan and blunt abdominal trauma severity score was calculated, decision was taken for further investigations and CT scan if the patient was stable. If patient was hemodynamic unstable, the patient was resuscitated and planned for emergency surgery if indicated.

Results: $64 \%$ were High risk $(\geq 12)$ according to blunt abdominal trauma severity score, $26 \%$ was of medium risk $(8-11)$, and only $10 \%$ was of low risk $(<8) 19 \%$ had perforated gut, $32 \%$ had spleen hematoma, $13 \%$ had liver tear, only $1 \%$ had kidney hematoma, and $1 \%$ had shattered spleen. There was non-statistical significant difference between presence or absence of mortality/morbidity and blunt abdominal trauma severity score, and there was statistical significant difference between procedure done and blunt abdominal trauma severity score.

Conclusion: BATSS can be a tool of early identification and stratification of patients blunt abdominal trauma, and it is a new scoring system based on clinical signs, can be used in predicting whether a blunt abdominal trauma patient needs laparotomy or not.
\end{abstract}

Keywords: The Blunt Abdominal Trauma Scoring System (BATSS), Mortality/ Morbidity, predicting, Death. 


\section{INTRODUCTION}

Trauma is damage to the body caused by an exchange with environmental energy that is beyond the body's resilience. Traumatic injuries remain the leading cause of death among patients aged 12-45 years and continue to account for substantial morbidity in this population (Magu et al., 2018).

Abdominal trauma is one of the most common causes among injuries caused mainly due to road traffic accidents. Motor vehicle accidents account for 75 to $80 \%$ of blunt abdominal trauma. Blunt injury of abdomen is also a result of fall from height, assault with blunt objects, sport injuries, and fall from riding bicycle. Blunt abdominal trauma is usually not obvious (O'Rourke et al., 2020).

Clinical examination plays an important role. History obtained from the patient or 1st responders helps to analyze the kinetics of the accident. Intestinal or mesenteric injury should be suspected in all high energy blunt traumas. Measurement of pulse, blood pressure, and hemo-dynamic state is the 1st priority (Borgialli et al., 2015).

Symptoms vary depending on what organ was injured because a perforated stomach tends to produce significant signs of peritonitis, due to the low $\mathrm{pH}$ of its contents, in comparison with fullthickness injuries to the small bowel, which may take a longer time to produce significant signs and symptoms. The retroperitoneal position of portions of the colon can also hinder the development of classic peritonitis (Van der Wilden et al., 2017).
Diagnostic tests in evaluation of abdominal trauma include X-ray erect abdomen, ultrasonography, diagnostic peritoneal lavage, computed tomography and diagnostic laparoscopy (Pikoulis et al., 2018).

Because of the difficulties to correctly characterize those lesions that require surgical repair and the wish to avoid operative delay, surgical exploration is carried out systematically for the least suspicion of intestinal or mesenteric injury (Killeen et al., 2016).

Blunt Abdominal Trauma Severity Score Clinical examination is combined with radiography and ultrasonography. The Blunt Abdominal Trauma Severity Score can be used as an initial screening to predict intra-abdominal organ injury and can be the basis of management in patients who experience blunt abdominal trauma (Karjosukarso et al., 2019).

A 24-point of blunt abdominal trauma Severity Score (BATSS) was developed based on $\beta$ sums obtained from each factor. The point of each factor was: abdominal pain, 2; abdomen tenderness, 3; chest wall sign, 1; pelvic fracture, 5; FAST, 8; SBP<100 mmHg, 4; PR> 100 beats/min (Vanitha and Prasanth, 2018). This score is tabulated in the proforma at the time of receiving the patient and the score is documented. Patients are classified into three groups based on the score (low risk $<8$, medium risk 8 to 11 and high risk $\geq 12$ ) (Magu et al., 2018).

The need for urgent surgery is obvious when one of the following clinical or CT signs is present hemodynamic instability, signs of frank peritonitis, loss of intestinal continuity, pneumoperitoneum, contrast 
extravasation and mesenteric ischemia (Mitsuhide et al., 2016).

At laparotomy, specific surgical procedures depend on the context. If the patient is hemodynamically unstable, an abbreviated damage control laparotomy should be performed. The two goals of abbreviated laparotomy are control of bleeding and reduction of the risk of digestive contamination (Sitnikov et al., 2016).

This study aimed to determine Blunt Abdominal Trauma patients' signs, as well as clinical data, and to clarify the accuracy, sensitivity, specificity, positive and negative predictive value of Blunt Abdominal Trauma Severity Score (BATSS).

\section{PATIENTS AND METHODS}

In this study, one hundred patients admitted with bunt abdominal trauma in Al-Hussein Hospital, Al- Azhar University, from March 2020 to October 2020.

Data collected included clinical history, and clinical examination with appropriate investigations.

After initial resuscitation and achieving hemodynamic stability, all patients were subjected to careful examination, and all patients underwent the FAST ultra sound and plain radiograph of chest and abdomen scan and blunt abdominal trauma severity score was calculated.

Decision was taken for further investigations and CT scan if the patient was stable. If patient was hemodynamic unstable, the patient was resuscitated and planned for emergency surgery if indicated.
Patients were followed up for a week to determine their possible need for laparotomy. The decision for operative or non-operative management depended on the outcome of the clinical examination and results of diagnostic tests. Patients selected for non-operative or conservative management was placed on strict bed rest, was subjected to serial clinical examination which included hourly pulse rate, blood pressure, respiratory rate and repeated examination of abdomen and other systems.

\section{Inclusion criteria:}

- All patients with blunt abdominal trauma less than 7 days.

- Both males and females.

- Age between 15 to 60 .

- Blunt abdominal trauma patients.

- Admitted cases with polytraumatized patients mainly blunt abdominal trauma.

\section{Exclusion criteria:}

- Any patient with abdominal trauma more than 7 days.

- Extreme of age under 15 and above 60 years.

\section{Statistical analysis:}

Data were fed to the computer and analyzed using IBM SPSS software package version 20.0. (Armonk, NY: IBM Corp) Qualitative data were described using number and percent. Quantitative data were described using range (minimum and maximum), mean, and standard deviation, median and interquartile range (IQR). Significance of the obtained results was judged at the 5\% level. Chi-square test: For categorical 
variables, to compare between different groups. Monte Carlo correction: Correction for chi-square when more than
$20 \%$ of the cells have expected count less than 5 .

\section{RESULTS}

This study was conducted on 100 cases which demographic data included 50 males $(50 \%)$ and 50 females (50\%). Their ages ranged from 18.0 to 60.0 years (mean \pm SD $38.53 \pm 12.11$ ); included majority of cases from 20 to 40 year (54\%). Road traffic accident was responsible for 19\% of cases, while assault from others accounted for $30 \%$ of cases and fall from height was responsible for $19 \%$ of injuries. $64 \%$ were high risk $(\geq 12)$ according to blunt abdominal trauma severity score, $26 \%$ was of medium risk $(8-11)$, and only $10 \%$ was of Low risk $(<8)$, and Mean \pm SD. of blunt abdominal trauma severity score was $12.66 \pm 3.72 .19 \%$ had perforated gut, $32 \%$ had spleen hematoma, 14\% had Retroper coll, 13\% had liver tear, only $1 \%$ had kidney hematoma, and $1 \%$ had shattered spleen. $19.5 \%$ had spleen grade 3, $19.5 \%$ had Ileal perforation, $17 \%$ had Jejunal perforation, 12.2\% had Liver lac, 9.8\% had spleen grade $4,9.8 \%$ had colon perforation, $4.9 \%$ had bladder tear, and only $4.9 \%$ had Stomach perforation. 59\% undergone Conservative method, $41 \%$ was undergone different surgical procedures. $17 \%$ was undergone splenectomy, primary repair was done in $12 \%$, hepatorraphy in $7 \%$, resect and anastomosis in $7 \%$, bladder repair in $2 \%$, gastric closure in $2 \% .92 \%$ were not admitted to ICU, Mean \pm SD. of hospital stay was $7.13 \pm 3.63$ days. $92 \%$ had neither morbidity nor mortality outcomes, $1 \%$ was died, and $7 \%$ had abdominal pain (Table 1).

Table (1): Distribution of the studied cases according to demographic data, mode of trauma, blunt abdominal trauma severity score, CT abdomen, clinical findings, surgical procedure, ICU and hospital stay and Mortality/Morbidity after 15 days from admission $(n=100)$

\begin{tabular}{|c|c|c|c|}
\hline \multicolumn{2}{|c|}{ Variables } & No. & $\%$ \\
\hline \multirow{12}{*}{$\begin{array}{c}\text { Demographic } \\
\text { data }\end{array}$} & Age (years) & & \\
\hline & $18-20$ & 6 & 6.0 \\
\hline & $21-30$ & 23 & 23.0 \\
\hline & $31-40$ & 31 & 31.0 \\
\hline & $41-50$ & 19 & 19.0 \\
\hline & $51-60$ & 21 & 21.0 \\
\hline & Min. - Max. & \multicolumn{2}{|c|}{$18.0-60.0$} \\
\hline & Mean \pm SD & \multicolumn{2}{|c|}{$38.53 \pm 12.11$} \\
\hline & Median(IQR) & \multicolumn{2}{|c|}{$37.50(29.50-49.0)$} \\
\hline & Sex & & \\
\hline & Male & 50 & 50.0 \\
\hline & Female & 50 & 50.0 \\
\hline \multirow{4}{*}{$\begin{array}{c}\text { Mode of } \\
\text { trauma }\end{array}$} & Assaults & 30 & 30.0 \\
\hline & Falls & 19 & 19.0 \\
\hline & Road Traffic Accident & 19 & 19.0 \\
\hline & Others & 32 & 32.0 \\
\hline
\end{tabular}


EVALUATION OF BLUNT ABDOMINAL TRAUMA SEVERITY...

\begin{tabular}{|c|c|c|c|}
\hline \multirow{6}{*}{$\begin{array}{c}\text { Blunt } \\
\text { abdominal } \\
\text { trauma severity } \\
\text { score }\end{array}$} & Low risk $(<8)$ & 10 & 10.0 \\
\hline & Medium risk $(8-11)$ & 26 & 26.0 \\
\hline & High risk $(\geq 12)$ & 64 & 64.0 \\
\hline & Min. - Max. & \multicolumn{2}{|c|}{$3.0-20.0$} \\
\hline & Mean \pm SD. & \multicolumn{2}{|c|}{$12.66 \pm 3.72$} \\
\hline & Median(IQR) & \multicolumn{2}{|c|}{$13.0(10.0-15.0)$} \\
\hline \multirow{9}{*}{ CT Abdomen } & Spleen hematoma & 32 & 32.0 \\
\hline & Perforated gut & 19 & 19.0 \\
\hline & $\begin{array}{l}\text { Retroperitonial } \\
\text { collection }\end{array}$ & 14 & 14.0 \\
\hline & Liver tear & 13 & 13.0 \\
\hline & Bladder tear & 2 & 2.0 \\
\hline & kidney hematoma & 1 & 1.0 \\
\hline & Shattered spleen & 1 & 1.0 \\
\hline & Free & 12 & 12.0 \\
\hline & Not done & 18 & 18.0 \\
\hline \multirow{11}{*}{$\begin{array}{l}\text { Clinical } \\
\text { Findings }\end{array}$} & Spleen grade 3 & 8 & 19.5 \\
\hline & Ileal perforation & 8 & 19.5 \\
\hline & Jejunal perforation & 7 & 17 \\
\hline & Liver laceration & 5 & 12.2 \\
\hline & Retroperitoneal & 5 & 12.2 \\
\hline & collection & 4 & 9.8 \\
\hline & Colon Perforation & 4 & 9.8 \\
\hline & Spleen grade 4 & 3 & 7.3 \\
\hline & Spleen grade 2 & 2 & 4.9 \\
\hline & Bladder tear & 2 & 4.9 \\
\hline & $\begin{array}{l}\text { Stomach perforation } \\
\text { Shattered spleen }\end{array}$ & 1 & 2.4 \\
\hline \multirow{2}{*}{ Management } & Conservative & 59 & 59.0 \\
\hline & Surgery & 41 & 41.0 \\
\hline \multirow{6}{*}{ Procedure } & Splenectomy & 17 & 17.0 \\
\hline & Primary repair & 12 & 12.0 \\
\hline & Hepatorraphy & 7 & 7.0 \\
\hline & Resect and anast & 7 & 7.0 \\
\hline & Bladder repair & 2 & 2.0 \\
\hline & Gastric closure & 2 & 2.0 \\
\hline \multirow{7}{*}{$\begin{array}{c}\text { ICU and } \\
\text { hospital stay }\end{array}$} & ICU & & \\
\hline & Not admitted & 92 & 92.0 \\
\hline & Admitted & 8 & 8.0 \\
\hline & Hospital stay & \multirow{4}{*}{\multicolumn{2}{|c|}{$\begin{array}{c}1.0-17.0 \\
7.13 \pm 3.63 \\
7.0(5.0-9.0) \\
\end{array}$}} \\
\hline & Min. - Max. & & \\
\hline & Mean \pm SD & & \\
\hline & Median(IQR) & & \\
\hline \multirow{3}{*}{$\begin{array}{l}\text { Mortality/ } \\
\text { Morbidity }\end{array}$} & Free & 92 & 92.0 \\
\hline & Died & 1 & 1.0 \\
\hline & Abdominal pain & 7 & 7.0 \\
\hline
\end{tabular}

There was a statistical significant difference between presence or absence of Mortality/Morbidity and Blunt abdominal trauma severity score where $\mathrm{p}$ value $=$ 0.01 (Table 2). 
Table (2): Blunt abdominal trauma severity score with Mortality/Morbidity ( $\mathrm{n=100)}$

\begin{tabular}{|c|c|c|c|c|c|c|c|}
\hline \multirow{2}{*}{ Mortality/ Morbidity } & \multicolumn{2}{|c|}{$\begin{array}{c}\text { Low risk } \\
(<8) \\
(\mathbf{n}=10)\end{array}$} & \multicolumn{2}{|c|}{$\begin{array}{c}\text { Medium risk } \\
\quad(8-11) \\
(n=26)\end{array}$} & \multicolumn{2}{|c|}{$\begin{array}{c}\text { High risk } \\
(\geq 12) \\
(\mathbf{n}=64)\end{array}$} & \multirow[t]{2}{*}{$\mathbf{P}$} \\
\hline & No. & $\%$ & No. & $\%$ & No. & $\%$ & \\
\hline No & 10 & 100.0 & 25 & 96.2 & 57 & 89.1 & \multirow{3}{*}{0.01} \\
\hline Died & 0 & 0.0 & 0 & 0.0 & 1 & 1.7 & \\
\hline Abdominal pain & 0 & 0.0 & 1 & 3.8 & 6 & 9.4 & \\
\hline
\end{tabular}

$\chi 2$ : Chi square test

MC: Monte Carlo

There was a statistical significant difference between procedure done and

Blunt abdominal trauma severity score where $\mathrm{p}$ value $<0.001$ (Table 3).

Table (3): Blunt abdominal trauma severity score with Procedure $(n=100)$

\begin{tabular}{|c|c|c|c|c|c|c|c|}
\hline \multirow{2}{*}{$\begin{array}{l}\text { Blunt abdominal } \\
\text { trauma severity } \\
\text { score }\end{array}$} & \multicolumn{2}{|c|}{$\begin{array}{c}\text { Low risk } \\
(<8) \\
(n=10)\end{array}$} & \multicolumn{2}{|c|}{$\begin{array}{l}\text { Medium risk } \\
\quad(8-11) \\
(n=26) \\
\end{array}$} & \multicolumn{2}{|c|}{$\begin{array}{c}\text { High risk } \\
(\geq 12) \\
(n=64)\end{array}$} & \multirow[t]{2}{*}{$\mathbf{P}$} \\
\hline & No. & $\%$ & No. & $\%$ & No. & $\%$ & \\
\hline Conservative & 10 & 100.0 & 24 & 92.3 & 25 & 39.1 & \multirow{7}{*}{0.001} \\
\hline Splenectomy & 0 & 0.0 & 0 & 0.0 & 17 & 26.6 & \\
\hline Primary repair & 0 & 0.0 & 1 & 3.8 & 11 & 17.2 & \\
\hline Hepatorraphy & 0 & 0.0 & 1 & 3.8 & 6 & 9.4 & \\
\hline Resect and anast & 0 & 0.0 & 0 & 0.0 & 7 & 10.9 & \\
\hline Bladder repair & 0 & 0.0 & 0 & 0.0 & 2 & 3.1 & \\
\hline Gastric closure & 0 & 0.0 & 0 & 0.0 & 2 & 3.1 & \\
\hline
\end{tabular}

$\chi 2$ : Chi square test, MC: Monte Carlo

\section{DISCUSSION}

This was a cross sectional study that was conducted on 100 cases admitted with bunt abdominal trauma in Al-Hussein Hospital, Al-Azhar University which included 50 males $(50 \%)$ and 50 females $(50 \%)$. Their ages ranged from 18.0 to 60.0 years included majority of cases from 20 to 40 year $(54 \%)$.

In agreement with our findings, the study of Vanitha and Prasanth (2018) reported that the total number of patients admitted with Blunt abdominal trauma by various General surgical Units in Madurai Medical College was 100, the majority of the patients belonged to 21-30 years age group, followed by 31-40 years age group and In the 100 cases studied, 88 cases were males, with females accounting for only about 12 cases. The retrospective study of Arumugam et al. (2015) reported that $15 \%$ had abdominal trauma and the majority was males $(93 \%)$.

In agreement with our findings, the study of Karjosukarso et al. (2019) reported that $50 \%$ has pulse rate $<100$ bpm, 75\% had abdominal pain, $77.3 \%$ had abdominal tenderness, $22.7 \%$ had chest wall sign, $88.6 \%$ had pelvic fracture, and FAST Score was positive in $86.4 \%$. Furthermore, they revealed that blunt abdominal trauma patients 
accompanied by pelvic fractures as many as $11.4 \%$ of patients and without pelvic fractures as much as $88.6 \%$ of patients. Demetriades et al. (2012) where in $16.5 \%$ of patients experienced blunt abdominal trauma associated with pelvic fractures.

Moreover, the previous study of Shojaee et al. (2014) showed that $62.5 \%$ had abdominal pain, $10.4 \%$ abdominal guarding, $75 \%$ abdominal tenderness, $35.4 \%$ abdominal wall sign, $20.8 \%$ rib tenderness, $16.7 \%$ chest wall sign and $16.7 \%$ pelvic fracture. Systolic blood pressure (SBP) lower than $100 \mathrm{mmHg}$, diastolic blood pressure (DBP) lower than $70 \mathrm{mmHg}$ and PR over 100 beats/min were recorded in $64.6 \%, 31.2 \%$ and $33.3 \%$ patients respectively. FAST results were positive detection of intra-abdominal free fluid in ultrasound in $87.5 \%$ IAI patients.

Blunt abdominal trauma is usually not obvious. The knowledge in the management of blunt abdominal trauma has progressively increasing due to the inpatient data gathered from different parts of the world. In spite of the best techniques and advances in diagnostic and supportive care, the morbidity and mortality remains at large. The reason for this could be due to the interval between trauma and hospitalization, delay in diagnosis, inadequate and lack of appropriate surgical treatment, postoperative complications and associated trauma especially to head, thorax and extremities (Vanitha and Prasanth, 2018).

In the present study, we revealed that $64 \%$ were High risk $(\geq 12)$ according to blunt abdominal trauma severity score, $26 \%$ was of medium risk $(8-11)$, and only $10 \%$ was of Low risk $(<8)$.
This was in comparison with the study of Shojaee et al. (2014) who reported that $66.1 \%$ of the patients were low, and $23.0 \%$ had a high score.

In the current study, and as regard distribution of the studied cases as regard CT findings, we found that $19 \%$ had perforated gut, $32 \%$ had spleen hematoma, $14 \%$ had Retro per coll, $13 \%$ had liver tear, only $1 \%$ had kidney hematoma, and $1 \%$ had shattered spleen, and it was found that $19.5 \%$ had spleen grade 3, 9.8\% had spleen grade $4,19.5 \%$ had Ileal perforation, $4.9 \%$ had bladder tear,9.8\% had colon perforation, $17 \%$ had Jejunal perforation, $12.2 \%$ had Liver laceration, and only $4.9 \%$ had Stomach perforation.

In a harmony with our findings, Hamidi et al. (2010) which was a retrospective analysis based on existing, diagnostic $\mathrm{CT}$ scan reports taken during a 5 year period from consecutive patients with blunt abdominal trauma, and reported that among the solid organ injuries, the spleen was the commonest organ involved.

Ninty five $\%$ has undergone conservative method, $41 \%$ undergone different surgical procedures, and as regard procedures done, $17 \%$ undergone splenectomy, primary repair was done in $12 \%$, hepatorraphy in $7 \%$, resect and anastomosis in $7 \%$, bladder repair in $2 \%$, and gastric closure in $2 \%$.

In contrary to our findings, Howes et al. (2012) included all blunt torso trauma patients admitted and observed that only $8 \%$ of blunt abdominal trauma patients required laparotomy. 
Karamercan et al. (2010) reported that emergency laparotomies were performed in $13 \%$ of the blunt abdominal trauma cases.

In our study, and as regard ICU admission and hospital stay; we demonstrated that $92 \%$ were not admitted to ICU, and majority $61 \%$ of hospitalized patients stay for one week. in agreement with our findings, the study of Arumugam et al. (2015) reported that the median length of the hospital stay was 8 days, the trauma ICU stay was 3 days and the median ventilatory days was 3 .

In addition to the above findings, we assessed the outcomes among participant cases and found that $92 \%$ had neither morbidity nor mortality outcomes, $1 \%$ was died, and $7 \%$ had abdominal pain. The study of Vanitha and Prasanth (2018) showed that the mortality is $8 \%$.

Sepsis or multiple organ dysfunction syndromes as a morbidity after severe abdominal trauma remains a substantial challenge and is expected to be the cause of late mortality. The overall incidence of sepsis in the work of Arumugam et al. (2015) was $1 \%$, and like our study, majority had neither morbidity nor mortality outcomes, the overall mortality was $8.3 \%$ and late mortality was observed in $2.3 \%$ cases mainly due to severe head injury and sepsis.

In contrast, an earlier study of Hildebrand et al. (2018) reported an incidence of morbidity following abdominal trauma of $11.3 \%$. In our study, the lower incidence of morbidity could be related in part to the young healthy patients with no associated comorbidities.
Another prospective study of Howes et al. (2012) on blunt abdominal trauma observed an overall mortality of $26 \%$ and half of these patients died of multiple organ failure secondary to sepsis. In comparison to other studies, the overall mortality in our cohort group was very low $(1 \%)$.

In the present study, we found that there was non- statistical significant difference between presence or absence of Mortality/Morbidity and Blunt abdominal trauma severity score, This was in contrary to the study of Vanitha and Prasanth (2018) where there is a strong correlation of higher CASS and BATS scores with increased mortality.

Interestingly, in the current study, there was a statistical significant difference between procedure done and blunt abdominal trauma severity score, which was supported by the study of Vanitha and Prasanth (2018) who recommend that, in the high risk group (score more > 12), immediate laparotomy should be done, moderate group needs further assessments, and low risk group should be kept under observation. Low risk patients did not show positive CT-scans (specificity100\%), and reported a significant relation between type of surgery and severity of BAT score.

\section{CONCLUSION}

The BATSS score system can be used as an initial screening to predict blunt abdominal trauma outcome and can be the basis of management in patients who experience blunt abdominal trauma.

\section{REFERENCES}

1. Arumugam S, Al-Hassani A and El-Menyar A. (2015): Frequency, causes and pattern of 
abdominal trauma: A 4-year descriptive analysis. Journal of Emergencies, Trauma, and Shock, 8(4): 193-198.

2. Borgialli DA, Ellison AM and Ehrlich P. (2015): Association betweenthe seat belt sign and intra-abdominal injuries in children withblunt torso trauma in motor vehicle collisions. Acad Emerg Med., 21(11): 1240-8.

3. Demetriades D, Karaiskakis M, Toutouzas K, Alo K, Velmahos G and Chan L. (2012): Pelvic Fractures: Epidemiology and Predictors of Associated Abdominal Injuries and Outcomes. Journal of American College of Surgeon, 195: 1-10.

4. Hamidi I, Aldaoud M and Qtaish I. (2010): The role of computed tomography in blunt abdominal trauma. Sultan Qaboos University Medical Journal, 7(1): 41-46.

5. Hildebrand D, Ben-Sassi A and Ross N. (2018): Modern management of splenic trauma. BMJ, 348: 1864-8.

6. Howes N, Walker T, Allorto NL, Oosthuizen GV and Clarke DL. (2012): Laparotomy for blunt abdominal trauma in a civilian trauma service. S Afr J Surg., 50:30-2.

7. Karamercan A, Yilmaz TU, Karamercan MA and Aytaç B. (2010): Blunt abdominal trauma: Evaluation of diagnostic options and surgical outcomes. Turk J Trauma Emerg Surg., 14:205-10.

8. Karjosukarso A, Wiargitha $\mathbf{K}$, Mahadewa $\mathbf{T}$ and Juwita N. (2019): Diagnostic validity of blunt abdominal trauma severity score (BATSS): on blunt adominal trauma in Sanglah General Hospital, Denpasar, Bali. Neurologico Spinale Medico Chirurgico, 2(1):16-19.

9. Killeen KL, Shanmuganathan $K$ and Poletti PA. (2016): Helical computed tomography of bowel and mesentericinjuries. Journal of Visceral Surgery, 51(1): 26-36.
10. Magu S, Agarwal S and Singh RG. (2018): Multi detector computed tomography in the diagnosis of bowel injury. Indian J Surg., 74(6): 445-50.

11. Mitsuhide K, Junichi $S$ and Atsushi N. (2016): Computed tomo-graphic scanning and selective laparoscopy in the diagnosisof blunt bowel injury: a prospective study. Journal of Visceral Surgery, 58: 696-73.

12. O'Rourke MC, Landis $R$ and Burns $B$. (2020): Blunt Abdominal Trauma. J Trauma Acute Care Surg., 165: 1081-1086.

13. Pikoulis E, Delis $S$ and Tsatsoulis P. (2018): Blunt injuries of the stomach. European Journal of Surgery, 165(10): 937-939.

14. Shojaee M, Faridaalaee G, Yousefifard M, Yaseri M, Arhami Dolatabadi A, Sabzghabaei A and Malekirastekenari A. (2014): New Scoring System for Intraabdominal Injury Diagnosis After Blunt Trauma. Chinese Journal of Traumatology, 17(1): 19-24.

15. Sitnikov V, Yakubu A, Sarkisyan V and Turbin M. (2016): The role of video-assisted laparoscopy in management of patients with small bowel injuries in abdominal trauma. Surg Endos., 23(1): 125-9.

16. van der Wilden GM, Velmahos GC, Emhoff T, Brancato S, Adams C and Georgakis G. (2017): Successful non operative management of the most severe blunt liver injuries: a multicenter study of the research consortium of new England centers for trauma. Arch Surgery, 147(5): 423-8.

17. Vanitha $T$ and Prasanth J. (2018): Prospective Study Comparing The Clinical Abdominal Scoring System (Cass) With Blunt Abdominal Trauma Severity Scoring (Batss) In Predicting The Necessity of Laparotomy. Journal of Dental and Medical Sciences, 17(3): 25-33. 
تقييم معيار شدة إصابات البطن الغير نافذه للتنبو ء بضرورة

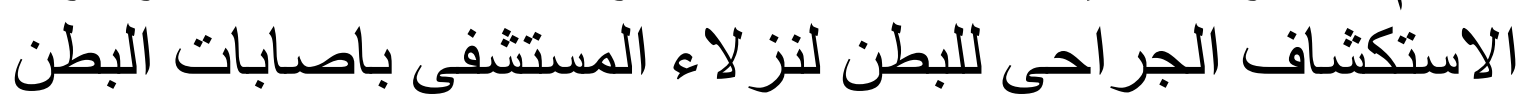
الغير نافذة

إسماعيل رجب السيد بلتاجى, محمود محمد أبو اليزيد محمود, إسلام طه ظلوش قسم الجراحة العامة, كلية الطب، جامعة الازهر

E-mail: ismaelbeltagy1235@gmail.com

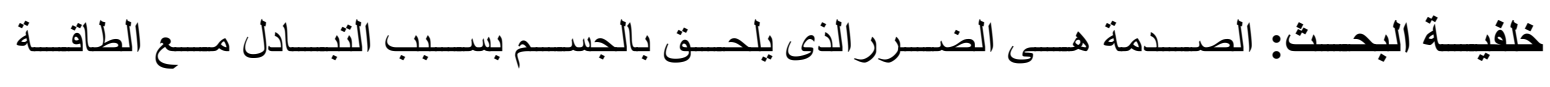

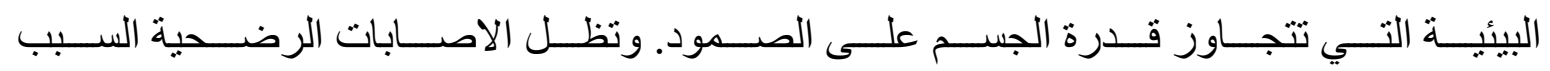

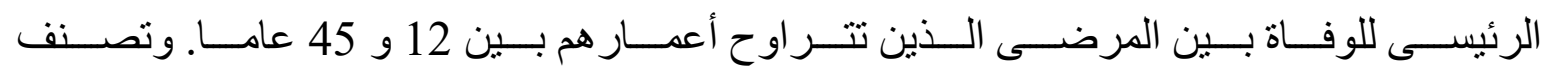

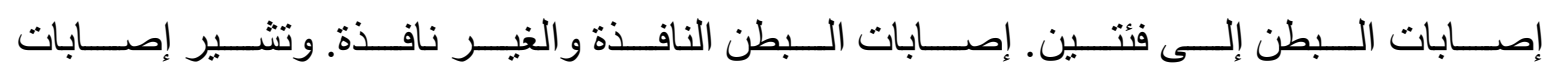

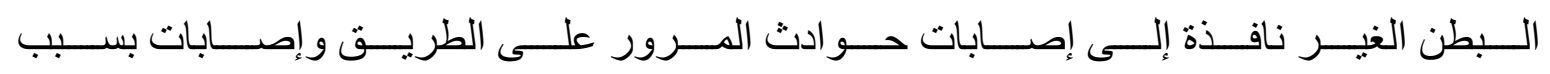

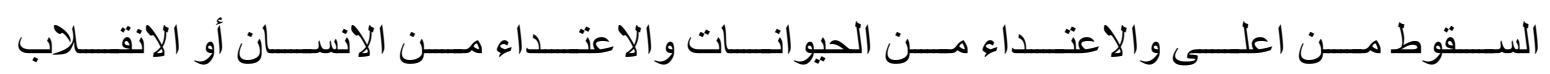
العكسي إلى التجويف البريتوني وتكون أكثر شيو عًا من الاصنابات البطن النافذة.

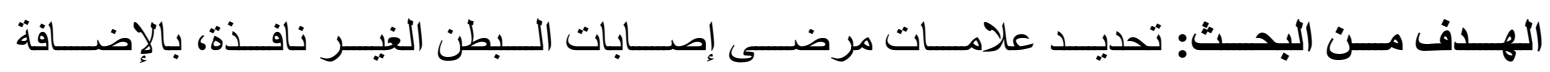

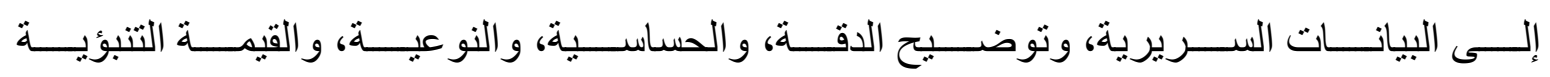

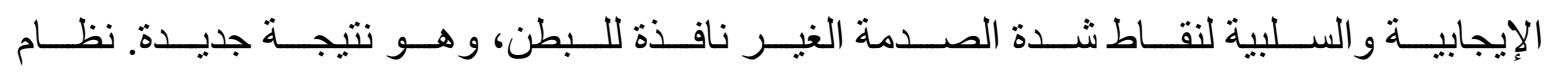

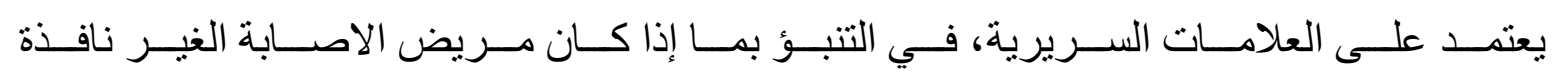
للبطن يحتاج إلى استكثاف جر احى للبطن أم لا.

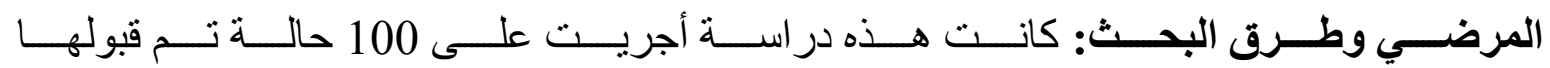

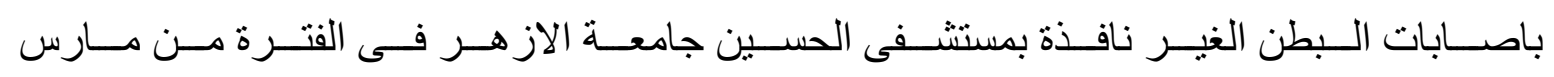

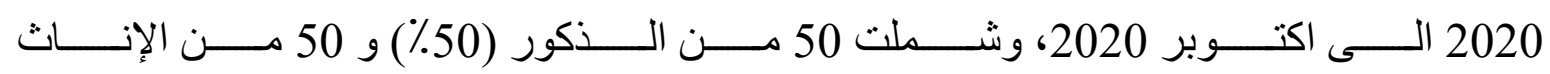

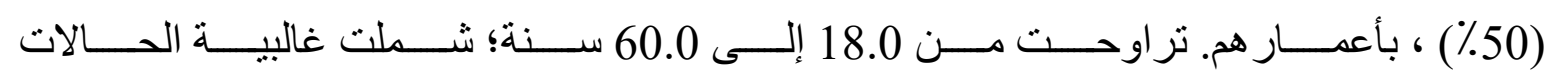

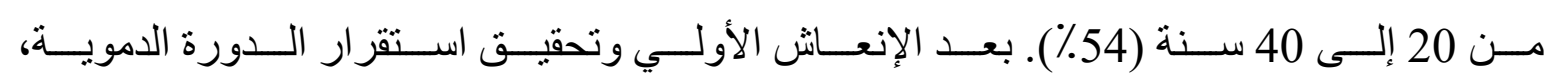

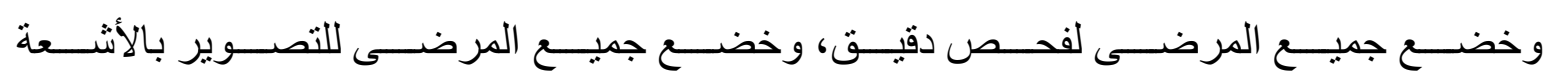

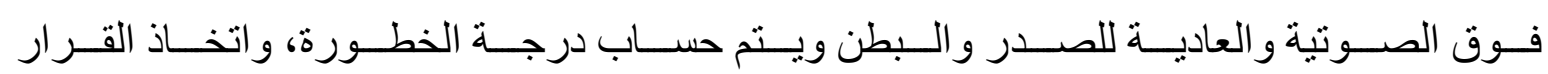

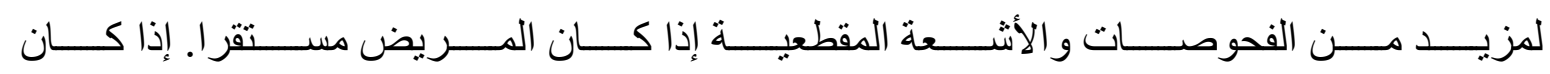




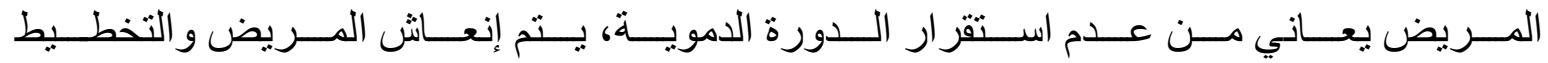
لعلية جر احية طارئة إذا لزم الأمر.

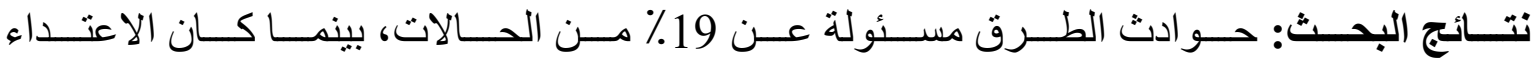

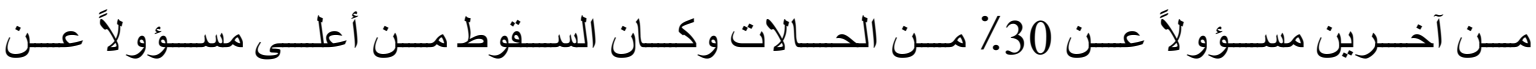

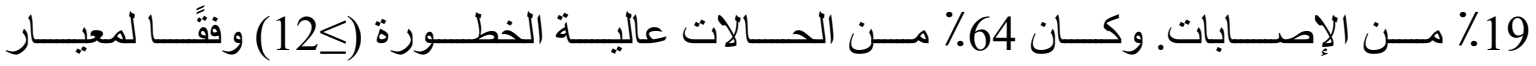

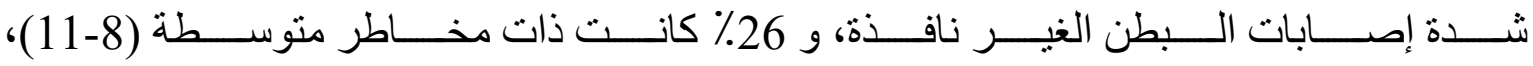

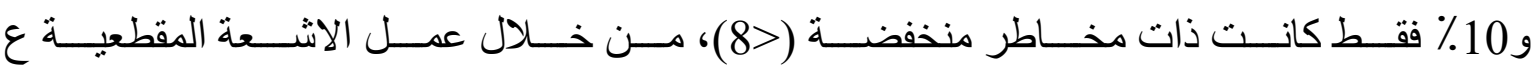

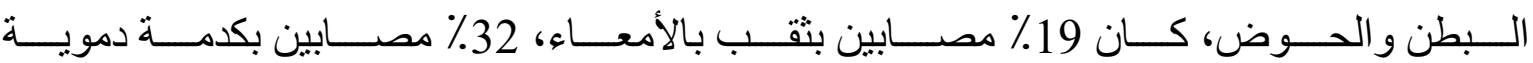

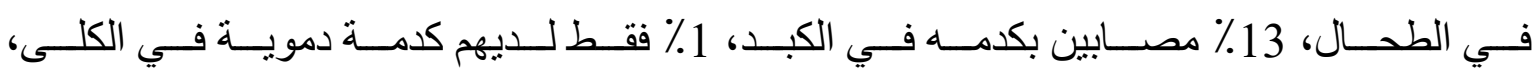

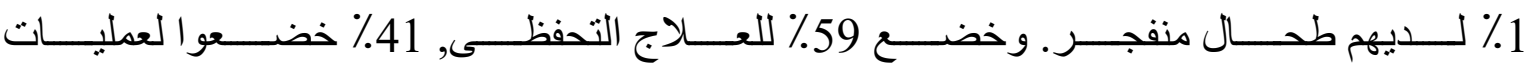

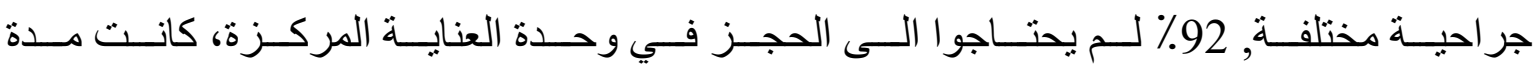

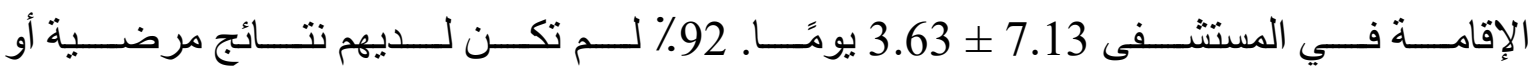

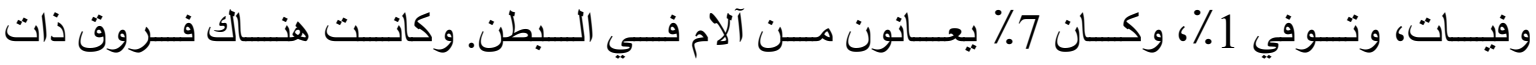

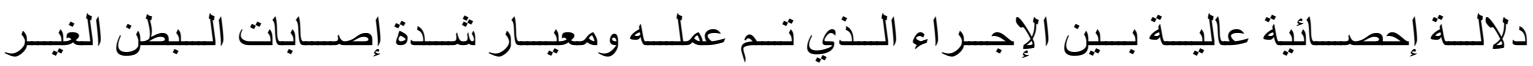

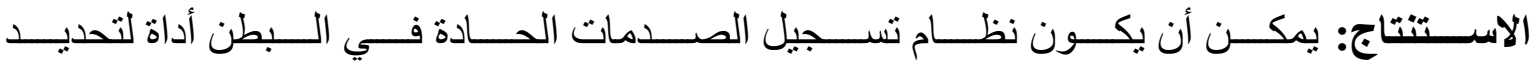

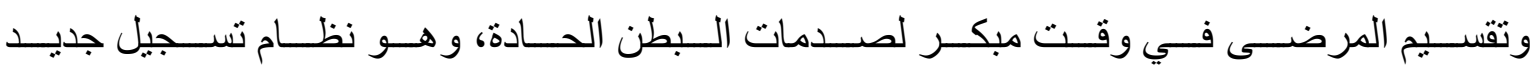

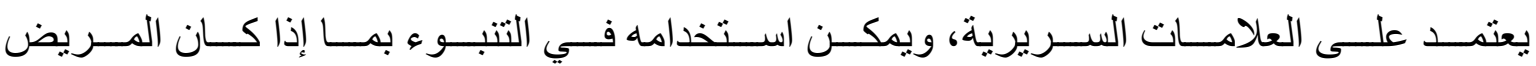
المصاب برضوض حادة في البطن يحتاج إلى شق البطن أم لا.

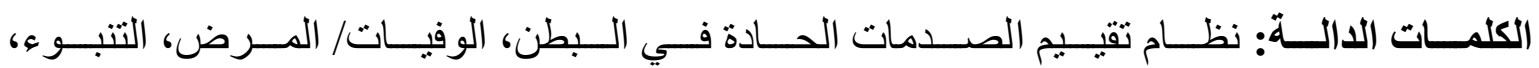
الموت. 